\title{
无人机遥感测绘技术在工程测绘中的应用分析
}

\author{
王光盈 \\ 山东正元数字城市建设有限公司 \\ DOI:10.32629/btr.v3i6.3164
}

\begin{abstract}
[摘要] 当前各国都比较重视无人机的研制工作,我国也在无人机研发的竞争行列里,并在创新的基础 上取得了可观的进步，很多国家都引进了我国研制的无人机产品，并应用了我国研发的技术。按照目前的 发展方向,我国可能会在未来的无人机市场上占有重要地位。无人机遥感技术也是我国无人机领域研发 的一项重要成果,应用无人机遥感技术的工作优势主要是可以快速收集和整理地理信息,精准度高,速度 快,效率高。可以看出,无人机技术在未来会有更大的发展空间。文章通过对无人机遥感技术优点进行分 析,全面提出新技术在工程测绘工作实际应用展望。
\end{abstract}

[关键词]工程测绘; 无人机; 遥感测绘

\section{1 无人机遥感测绘优点}

1. 1 提高数据准确性

无人机遥感技术的全面应用, 有效 提高了数据准确性, 使收集到的数据更 加安全, 为各类工程建设提供优质的保 障。无人机遥感技术较为复杂, 是各种技 术的集合, 特别是卫星定位、数码传感及 无人技术等新技术的应用, 全面提高了 数据收集效率与质量, 大大的减少了测 绘误差, 保证了数据快速收集, 高科技的 应用全面提高了数据准确性。随着无人 机技术的不断改进, 无人技术越来越成 熟完善, 在各个领域都发挥着作用, 无人 机的体积小、灵活性、操作简便等特点, 对工程测绘起到了推动, 特别是在复杂

节, 在此过程中技术管理人员应针对图 纸、人员、技术以及材料、设备等多方 面进行综合管理, 任何一个环节出现问 题均可能会造成十分严重的施工问题。 如在图纸方面, 施工图纸并不是一蹴而 就的, 且施工过程中往往会发生特殊情 况, 而一旦发生此种情况则需要对图纸 进行更改, 不断优化施工技术方案, 另外, 在施工中要做好材料、设备的质量检查 工作, 确保不会有不符合使用规格的材 料、设备进入施工现场, 人员方面主要是 使施工人员能够做到严格按照施工标准 进行施工, 一旦发现问题必须及时纠正。
的区域, 能够对测绘区域进行详细勘察, 通过软件的使用, 后期形成再次数据加 工, 就避免了数据的失误与丢失, 确保了 数据安全与精准。

\section{2 提高效率}

无人机遥感技术有效提高了工作的 效率, 通过技术的全面应用, 减少了人工 操作程序, 使工作速度得到提升, 各种软 件的应用也大大减少了误差, 保证了数 据的快速处理能力, 对数据快速处理不 但提高了工作效率, 更使数据准确性得 到保障。使用无人机进行外部作业, 不受 恶劣天气影响, 避免了人员的伤亡, 无人 机能够在各种天气状况下进行工作, 保 证了测绘的进度, 和传统使用飞机进行
测绘的作业相比, 无人机续航时间更长, 全面提高了工作效率, 保证了数据质量。

\section{3 机动灵活}

无人机体型相对较小, 运行速度较 快, 且更加灵活。在实际的应用过程当中, 拍摄的画面也更加清晰, 图像处理技术 更好。在传统的工程测绘过程中, 借助无 人机航拍技术, 需要投入大量的人力, 物 力和财力, 在一定程度上会增加建筑工 程项目的工程造价和投资成本。而借助 无人遥感测绘技术, 能够有效降低工程 项目测绘所投入的成本。同时, 能够让工 程测绘趋向于无人化, 高效化。在实际的 应用过程中, 可以不间断的进行航拍。而 借助相应的计算机技术, 能够有效提高

\section{4 结论}

在进行市政工程施工的过程中, 施 工企业应加强施工阶段的技术管理。需 要相关工作人员遵循一定的管理原則, 及时发现现状中存在的主要问题, 及时 制定相应的对策方案, 从而保证工程能 够顺利的全面开展, 在为企业提高优良 的业绩和经济效益的同时, 使市政工程 建设能够更好地为人们生活服务, 更好 地促进社会经济建设。

\section{[参考文献]}

[1]李文兵.市政工程施工各阶段技术 管理要点[J]. 山西建筑,2016,(22):232-233.
[2]杨荟锦。市政工程施工各阶 段技术管理要点分析 [J]. 建材与装 饰,2016,(50):152-153.

[3]邤富炳.市政工程施工各阶段技 术管理要点分析 [J]. 建筑工程技术与设 计,2016,(31):1296.

[4]李业坚.市政工程施工节能绿色环 保技术[J].低碳世界,2020,10(5):18+20.

[5]戴文雄.市政工程路基填筑施工 技术简述[J].居舍,2020,(15):36.

[6]李亮,李国庆。市政施工技术 质量管理的相关分析 [J]. 建材与装 饰,2020,(18):201+205. 
无人机技术测绘的准确性。无人机技术 最大的优势则是其测绘过程相对较灵活, 能够高效开展相应的工作, 减少不必要 的资金投入。

\section{2 无人机遥感技术在工程测绘 中的实际应用}

\section{1 数据采集}

工程建设离不开精准的数据, 只有 测绘精度达到要求, 才能建设高品质的 项目产品。那么, 工程测绘数据收集就显 得非常重要, 良好的数据支撑是工程决 策的重要依据, 通过数据分析, 全面做好 工程的谋划与设计。在各种工程测绘工 作中, 已经大量的使用到了无人机遥感 技术, 帮助工程人员采集各种有用数据, 同时, 还能够及时的进行汇总分析, 使数 据收集速度提高, 精度更高。在实际操作 过程中, 需要相关操作人员对计算机输 入指令, 对测绘的区域进行划分, 合理设 计好无人机航线, 在合理的环境条件下, 让无人机执行设计的指令, 在飞行过程 中, 无须操作只要保证无人机的安全, 就 能够得到相关的数据, 顺利完成工程测 绘工作。当前, 随着技术的不断创新, 无 人机已经实现了借助定位系统进行精准 定位的功能, 根据对应的坐标系统, 保证 一定范围的测绘作业能力。对于获取的
各种资料, 需要做好复核与检测, 保证数 据精确, 然后再二次飞行, 对需要的数据 进行补充, 全面提高数据精准度。

\section{2图像采集}

工程测绘除了对数据进行收集, 还 需要对各种图像进行收集与整理, 全面 满足制图的需要, 图像收集是必不可少 的一个内容。通过使用无人机技术, 能够 对测绘范围内的信息进行收集, 形成影 像拍摄, 另外, 还能够利用三维建模对拍 摄画面进行再次深入加工, 为制图工作 提供有效指导。无人测绘智能化较高, 对不符合要求的图像能够自动处理, 系 统能够对图像进行处理, 对重叠影像数 码相机会自动变焦, 实现对图像参数的 有效快速调整, 有效确保了收集到的图 像更加清晰。

\section{3 低空作业}

无人机的使用, 极大的保证了安全 性, 特别是一些工程测绘项目, 必须要有 清晰的图像与精准的数据, 在一些较差 环境作业时, 无人机低空飞行更加灵活, 不受外部条件影响就能够完成测绘任务, 无人机能够在复杂环境中适应飞行, 在 保证自身安全的前提下, 安全快速的完 成各种指令。随着技术的不断完善, 无人 机低空作业遥感技术也在不断的升级,
有效提升了无人机快速应对能力, 提高 了测绘的整体效果与质量。

\section{3 结束语}

无人机遥感测绘技术对工程测绘起 到重要的作用, 给工程测绘工作带来较 大便利, 只有不断强化推广, 才能在实践 中总结经验, 不断优化技术, 促进测绘事 业健康发展。

\section{[参考文献]}

[1]韩晋榕.在工程测绘中无人机遥 感测绘技术的应用探析 [J]. 华北国土资 源,2018(04):61-62.

[2]李建伟.无人机遥感测绘技术在 工程测绘中的应用探究 [J]. 山东工业技 术,2018(10):139.

[3]徐莉. 无人机遥感技术在测 绘工程测量中的应用 [J]. 中外企业 家,2018(13):92

[4]周培诚.无人机遥感技术在测绘 工程中的有效应用分析 [J].世界有色金 属,2020(03): $37+39$.

[5]张洁.无人机遥感测绘技术在工 程测绘中的应用探究[J].信息与电脑(理 论版),2019(15):13-15.

[6]何瑛.无人机遥感技术在青海地 区工程测绘中的发展及应用探讨[J].工 程技术研究,2018(06):95-96. 